\title{
AIRCRAFT CONTROL DESIGN WITH LINEAR AND NON LINEAR TECHNIQUES: COMPARATIVE ASPECTS
}

\author{
Daniel Luis Cerignoni ${ }^{1}$, Danilo Grima Galisteu ${ }^{1}$, Giannino Ponchio Camillo ${ }^{1}$, Ney Rafael Sêcco ${ }^{1}$, Francisco \\ Triveño $\operatorname{Vargas}^{1}$, Pedro Paglione ${ }^{1}$ \\ ${ }^{1}$ Technological Institute of Aeronautics \\ São José dos Campos, SP, Brazil
}

\begin{abstract}
In this paper is detailed a linear LQR control technique, when applied the specific weighting algorithm. This is done as a preamble to the implementation of gain schedule technique, already established in the industry. Latter, the nonlinear backstepping technique is presented; its characteristics and design methodology are highlighted, looking its industrial implementation. Finally comparative aspects between both techniques are discussed, this is done taking into account the same controlled variable, the same reference input and the same control surface (i.e. actuator). Aspects such as the ease of designing, real -time implementation, the structure migration for different aircraft projects, certification and others are considered. The paper contains innovations aspects related to design of nonlinear technique and the comparison with gain scheduling looking its industrial application.
\end{abstract}

Keywords: flight control, nonlinear control, backstepping, linear quadratic regulator, gain scheduling.

\section{NOMENCLATURE}

\begin{tabular}{|c|c|c|}
\hline Symbol & Definition & Unit \\
\hline$I_{y}$ & Aircraft inertia & $\begin{array}{l}\text { slug } \\
\cdot f t^{2}\end{array}$ \\
\hline$m$ & Aircraft mass & slug \\
\hline$\propto$ & Angle of attack & rad \\
\hline$D$ & Drag force & $l b f$ \\
\hline $\bar{q}$ & Dynamic pressure & $p s f$ \\
\hline$\delta_{e}$ & Elevator deflection & deg \\
\hline$F_{T}$ & Engine thrust force & $l b f$ \\
\hline$\gamma$ & Flight path angle & rad \\
\hline$g$ & Gravitational acceleration & $f t / \mathrm{s}^{2}$ \\
\hline$L$ & Lift force & $\operatorname{lbf}$ \\
\hline$n_{Z}$ & $\begin{array}{l}\text { Load factor, normal } \\
\text { acceleration }\end{array}$ & $g$ \\
\hline$\theta$ & Pitch angle & rad \\
\hline$q$ & Pitch rate & $\mathrm{rad} / \mathrm{s}$ \\
\hline$M$ & Pitching inertia & $l b \cdot f t$ \\
\hline$V_{T}$ & Total velocity & $f t / \mathrm{s}^{2}$ \\
\hline$S$ & Wing area & $f t^{2}$ \\
\hline$C_{Z}$ & $\begin{array}{l}\mathrm{z} \text {-axis aerodynamic force } \\
\text { coefficient }\end{array}$ & - \\
\hline$z_{T P}$ & $\begin{array}{l}Z_{b} \text {-position of engine } \\
\text { thrust point }\end{array}$ & $f t$ \\
\hline \multicolumn{3}{|c|}{ subscripts } \\
\hline 0 & value at initial time & - \\
\hline$c$ & value compensated & - \\
\hline ss & value at steady state & - \\
\hline \multicolumn{3}{|c|}{ superscripts } \\
\hline ref & value at reference & - \\
\hline
\end{tabular}

\section{INTRODUCTION}

The design of flight control systems is a typical nonlinear control problem, due directly to the changes in aircraft dynamics with flight conditions and aircraft configuration. For this reason, a dynamic mode that is stable and adequately damped in one flight condition may become unstable or at least inadequately damped in another one. In commercial aircraft, a lightly damped oscillatory mode may cause a great deal of discomfort to passengers or make it difficult for the pilot to control the aircraft. For a combat aircraft, this condition may lead to more critical situation because the aircraft is already inherently unstable due the maneuverability requirements and capability of attack.

These problems are overcome by using feedback control to modify the aircraft dynamics which also bring along improvements in terms of aircraft weight diminution, aerodynamic efficiency and optimization of fuel consumption. These changes are naturally leading that the design of new airplanes to have embedded relaxed stability, boosting the use of feedback control laws (F. and da Costa, 2006). Such control laws are known in the aeronautical lingo as Stability Augmentation System (SAS) if is necessary to change the damping and the natural frequencies of aircraft modes and Control Augmentation System (CAS) if the purpose is to control the modes providing the pilot with a particular type of aircraft response. In this paper, two strategies are used to design and simulate a normal acceleration controller: the gain scheduling and backstepping techniques. 
Gain scheduling is considered a standard method to design Linear Time Invariant (LTI) controllers for nonlinear systems. It also has widespread and successful engineering applications. In the aerospace industry, this technology was first used on military applications; see We Leithead, (1999). Research of gain scheduling applications in civil aircraft and other areas developed gradually since then, examples of its implementation in aircraft control are Dagfinn Gangsaas, John Hodgkinson et. al, (2008), and Alex S. F. da Silva et. al, (2011).

Gain scheduling is an attractive control strategy to deal with nonlinearities in aircraft. The main idea of this methodology is to design a set of LTI controllers for specific operating points over the flight envelope and then to interpolate the gains against the current value of the scheduling parameters (flight conditions), instead of seeking a single robust LTI controller for the entire operating range.

Backstepping technique constitutes an alternative to gain scheduling. Using backstepping, the nonlinearities of the system do not have to be canceled in the control law. If a nonlinearity acts in a stabilizing way, and thus in a sense is useful, it may be retained in the closed loop system see Chieh Chen, (1996).

The backstepping technique appeared implicitly in several papers in the late 1980's. However, it received important attention after the works of Professor Petar V. Kokotovic and coworkers circa 1990.

Regarding aircraft flight control applications, previous nonlinear flight control designs were typically based on feedback linearization, called nonlinear dynamic inversion (NDI) by the flight control community, see Meyer et al. (1984), Lane and Stengel (1988), and Enns et al. (1994). Most importantly, Härkegård and Glad (2000) introduced a backstepping design procedure for flight path angle control, and the next year they investigated backstepping as a new framework for a complete nonlinear flight control design, see Härkegård and Glad (2001).

More recently, important research of backstepping technique for aircraft flight control is being done at Delft University of Technology, where Sonneveldt, L., (2010), proposed the design of a stability and control augmentation system for a modern fighter aircraft using a nonlinear adaptive backstepping method with handling qualities evaluation. Another important work was produced at Aeronautics Institute of Technology (ITA) Brazil by Morales A. et. al (2011), in which a control system based on backstepping for a flexible medium transport aircraft was developed. Finally, a survey of adaptive backstepping control and safety analysis for modern fighter aircraft is presented in Van Oort (2011).

The main contribution of this paper is to compare the techniques of Gain Scheduling and Backstepping as an initial step to industrial implementation of nonlinear techniques in the future.

In section 2 the mathematical model of aircraft is described. The characteristics and design of gain scheduling technique are presented in section 3 . Main characteristics and design of backstepping controller are discussed in section 4. Comparative aspects between both techniques and results are presented in section 5. Finally, the conclusions of this study are presented.

\section{AIRCRAFT MODELING}

The nonlinear six-degree-of-freedom F-16 aircraft model adopted was the downloadable MATLAB package developed by Ying Huo that uses data from NASA-Langley wind-tunnel tests on a scale model of an F-16 airplane. The data apply to the speed range up to about Mach=0.6.

For the longitudinal dynamic of an airplane we have the follow equations that determine its translation and rotation behaviors:

$$
\begin{aligned}
& \dot{V}_{T}=\frac{1}{m}\left(-D+F_{T} \cos \alpha-m g \sin \gamma\right) \\
& \dot{\alpha}=q+\frac{1}{m V_{T}}\left(-L-F_{T} \sin \alpha+m g \cos \gamma\right) \\
& \dot{\gamma}=\frac{1}{m V_{T}}\left(L+F_{T} \sin \alpha-m g \cos \gamma\right) \\
& \dot{\theta}=q \\
& \dot{q}=\frac{1}{I_{y}}\left(M+F_{T} Z_{T P}\right)
\end{aligned}
$$

\section{GAIN SCHEDULING}

This section presents the application of the Gain Scheduling methodology to implement a load factor tracker for a non-linear F-16 model. 


\section{i. INTRODUCTION}

The LQR (Linear Quadratic Regulator) is one the most fundamental applications of the Optimal Control. The fact that this method simultaneously determines all the gains in a MIMO system controller is one of its main appeals. It is also very robust when considering uncertainties in the system's model (Lewis and Stevens, 2003).

The LQR problem can be transformed into an LQT (Linear Quadratic Tracker) problem through a change of variables. Instead of regulating the system around an equilibrium point, the new objective is to follow a reference signal. The control structure presented in Figure 1 was used to derive the LQT relationships.

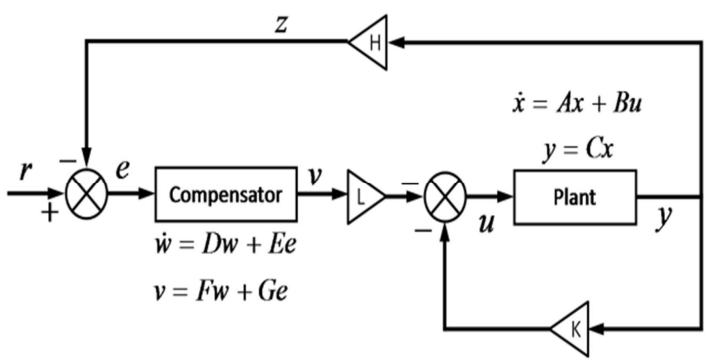

Figure 1. LQT Structure

The controls structure of the Figure 1 may be translated into the following equations:

- Plant Dynamics:

$$
\begin{aligned}
& \dot{x}=A x+B u \\
& y=C x \\
& \dot{w}=D w+E e \\
& v=F w+G e \\
& e=r-H y \\
& u=-K y-L v
\end{aligned}
$$$$
\text { - Compensator Dynamics: }
$$

- Tracking Error

The main goal of the LQT is to adjust the gains $K$ and $L$ in order to minimize a certain cost function. It is possible to generate an equivalent system merging the Plant's and the Compensator's Dynamics. Using elemental matrix algebra, the following relationships may be derived:

$$
\begin{gathered}
\dot{\bar{x}}=A_{C} \bar{x}+B_{C} r \\
u=-C_{C} \bar{x}-D_{C} r \\
e=-H_{C} \bar{x}+r
\end{gathered}
$$

Where $\bar{x}=\left[\begin{array}{ll}x & w\end{array}\right]^{T}$ is the merging of the Plant's and the Compensator's states and:

$$
\begin{aligned}
& A_{C}=\left[\begin{array}{cc}
A-B K C+B L G H C & -B L F \\
-E H C & D
\end{array}\right] \\
& B_{C}=\left[\begin{array}{c}
-B L G \\
E
\end{array}\right] \\
& C_{C}=\left[\begin{array}{ll}
K C-L G H C & L F
\end{array}\right] \\
& D_{C}=[L G] \\
& H_{C}=\left[\begin{array}{ll}
H C & 0
\end{array}\right]
\end{aligned}
$$

A shift in the variables is necessary to define a closed-loop system for the LQR application. Consider the following variable changes, where the subscript SS indicates the value of the variable at the steady state:

$$
\begin{aligned}
& \tilde{x}=\bar{x}-\bar{x}_{S S} \\
& \tilde{u}=u-u_{S S} \\
& \tilde{e}=\bar{e}-e_{S S}
\end{aligned}
$$

Given a reference signal $r_{0}$, the states at the steady state may be given by:

$$
\begin{gathered}
\dot{\bar{x}}=0 \rightarrow A_{C} \bar{x}_{S S}+B_{C} r_{0}=0 \\
\bar{x}_{S S}=-A_{C}^{-1} B_{C} r_{0}
\end{gathered}
$$

Thus, the Tracking Error at the steady state may be given by:

$$
\begin{gathered}
e_{S S}=-H_{C} \bar{x}_{S S}+r_{0} \\
e_{S S}=\left(H_{C} A_{C}^{-1} B_{C}+I\right) r_{0}
\end{gathered}
$$

Applying the variable changes, the following system is found:

$$
\begin{gathered}
\dot{\tilde{x}}=A_{C} \tilde{x} \\
\tilde{u}=-C_{C} \tilde{x} \\
\tilde{e}=-H_{C} \tilde{x}
\end{gathered}
$$

The cost function selected penalizes the controller's performance, the control's effort and the steady state error. The first parcel is weighted by $t^{5}$ in order to privilege solutions with smaller transient time.

$$
J=\frac{1}{2} \int_{0}^{\infty}\left(h \cdot t^{5} \tilde{e}^{T} \tilde{e}+\tilde{u}^{T} R \tilde{u}\right) d t+\frac{e_{S S}^{T} V e_{S S}}{2}
$$

$h, R$ and $V$ are weights used to differently penalize each parcel.

Lewis and Stevens (2003) show that this cost function can be calculated using successive applications of the Lyapunov equation. 
ii.

\section{DESIGN}

For the longitudinal load factor tracker of the F-16 fighter, a Proportional-Integrator Compensator was considered. An SAS for angle of attack and pitch rate was also implemented, resulting in the structure presented in Figure 2.

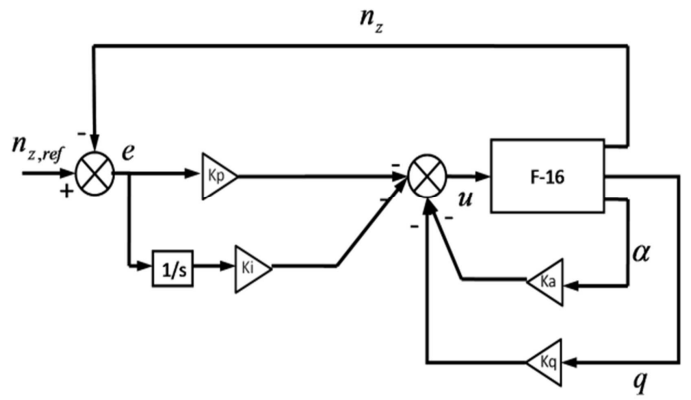

Figure 2. LQT Structure applied to the F-16 case study.

This structure is composed the following matrices:

$$
\begin{aligned}
& u=\left[\delta_{e}\right] \\
& y=\left[\begin{array}{lll}
n_{z} & \alpha & q
\end{array}\right]^{T} \\
& H=\left[\begin{array}{lll}
1 & 0 & 0
\end{array}\right] \\
& D=0 \\
& E=1 \\
& F=\left[\begin{array}{ll}
1 & 0
\end{array}\right]^{T} \\
& G=\left[\begin{array}{ll}
0 & 1
\end{array}\right]^{T} \\
& K=\left[\begin{array}{lll}
0 & K_{a} & K_{q}
\end{array}\right] \\
& L=\left[\begin{array}{ll}
K_{i} & K_{p}
\end{array}\right]
\end{aligned}
$$

The matrices $\mathrm{A}, \mathrm{B}$ and $\mathrm{C}$ are given by linearization of the F-16 model.

The LQT needs a linear model of the Plant. It is known that a non-linear system can be linearized around an equilibrium point. But non-linear systems, such as aircrafts, have several equilibrium states. Using fixed gains, which were adjusted for a single equilibrium point, may result in a poor controller's performance. Then the Gain Schedule is a global solution to broadly cover the operational envelope of the system.

The Gain Schedule procedure consists in applying the LQT at linear models generated at distinct equilibrium points, what results in a look-up table of gains. So the controller's gains are settled using an interpolation between the current state of the system and the equilibrium states.
For the F-16 test case, the airplane was trimmed for TAS (True Air-speed) ranging from $350 \mathrm{ft} / \mathrm{s}$ to $600 \mathrm{ft} / \mathrm{s}$, with steps of $50 \mathrm{ft} / \mathrm{s}$. Linearized models were generated for each condition.

The LQT was applied at each of these models. An extensive study was performed in order to select the appropriate weights of the cost function. Different sets of weights were used at each equilibrium condition.

The gains, the controls and the states at each equilibrium point were stored in 7 onedimensional look-up tables, using TAS as interpolation variable: 4 tables for the gains, 2 tables for controls (elevator and throttle) and 1 table for states (angle of attack).

\section{The}

Figure 3 shows how the gains vary with the TAS.

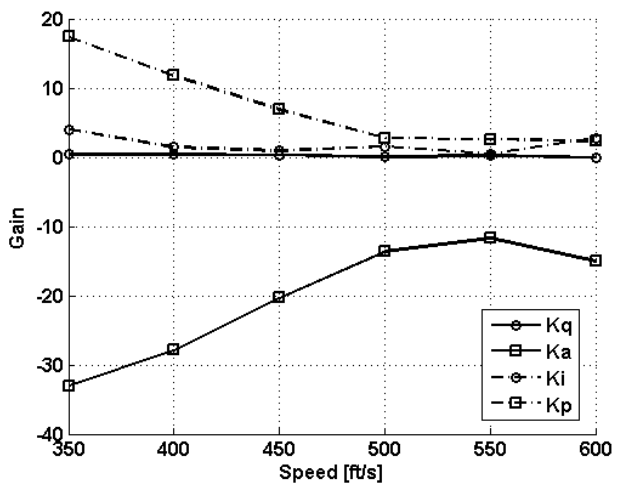

Figure 3. Gain Schedule obtained using LQT. A computational model was implemented in Simulink ${ }^{\circledR}$ in order to numerically simulate the Gain Schedule Controller.

\section{BACKSTEPPING}

Backstepping is a systematic, Lyapunov-based method for nonlinear control design. The name "backstepping" refers to the recursive nature of the design procedure. The design procedure starts at the scalar equation which is separated by the largest number of integrations from the control input and 'steps back' toward the control input. Each step an intermediate or 'virtual' control law is calculated and in the last step the real control law is found (Sonneveldt, 2010). 


\section{i. LYAPUNOV THEORY IN CONTROL DESIGN}

Consider the nonlinear dynamical system

$$
\begin{gathered}
\dot{x}=f(x(t), t) \\
x\left(t_{0}\right)=x_{0}
\end{gathered}
$$

where $x(t) \in \mathfrak{R}^{n}$ and $f: \mathfrak{R}^{n} \times \mathfrak{R}^{+} \rightarrow \mathfrak{R}^{n}$.

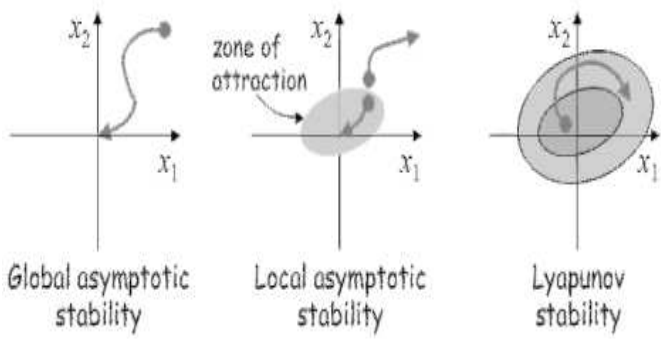

Figure 4. Types of stability.

The Lyapunov's Direct Method is a generalization of the idea that if there is some 'measure of energy' in a system, then studying the rate of change of the energy in the system is a way to ascertain stability. Using these definitions, the following theorem can be used to determine stability for a system by studying an appropriate Lyapunov (energy) function V (x,t), called Control Lyapunov Function (CLF). The time derivative of $\mathrm{V}(\mathrm{x}, \mathrm{t})$ is taken along the trajectories of the system (12).

$$
\left.\dot{V}\right|_{\dot{x}=f(x, t)}=\frac{\partial V}{\partial t}+\frac{\partial V}{\partial t} f(x, t)
$$

Now, consider the nonlinear system to be controlled

$$
\begin{gathered}
\dot{x}=f(x, u) \\
x \in \mathfrak{R}^{n}, u \in \mathfrak{R} \\
f(0,0)=0
\end{gathered}
$$

where $x$ is the system state and $u$ the control input. The control objective is to design a feedback control law $\alpha(\mathrm{x})$ for the control input $\mathrm{u}$ such that the equilibrium $\mathrm{x}=0$ is globally asymptotically stable. To prove stability a function $V(x)$ is needed as a Lyapunov candidate, and it is required that its derivative along the solutions of (14) satisfies $\dot{V}(x) \leq-W(x)$, where $W(x)$ is a positive semi-definite function (Sonneveldt 2010). The straightforward approach for finding $\alpha(x)$ would be to pick a positive definite, radially unbounded function $V(x)$ and then choosing $\alpha(x)$ such that:

$$
\frac{\partial V}{\partial x}(x) f(x, \alpha(x)) \leq-W(x), \quad x \in \mathfrak{R}^{n}
$$

To illustrate the Backstepping design approach, consider the second order system:

$$
\begin{aligned}
& \dot{\mathrm{x}}_{1}=\mathrm{f}\left(\mathrm{x}_{1}\right)+\mathrm{g}\left(\mathrm{x}_{1}\right) \mathrm{x}_{2} \\
& \dot{x}_{2}=u
\end{aligned}
$$

where $\left(x_{1}, x_{2}\right) \in \Re^{2}$ are the states, $u \in \mathfrak{R}$ is the control input and $g\left(x_{1}\right) \neq 0$. In Sonneveldt (2010) this tracking control problem can be transformed to a regulation problem by introducing the tracking error variable $z_{1}=x_{1}-$ $y_{r}$ and rewriting the $x_{1}$-subsystem in terms of this variable as:

$$
\dot{z}_{1}=f\left(x_{1}\right)+\mathrm{g}\left(x_{1}\right) x_{2}-\dot{y}_{r}
$$

Since $x_{2}$ is just a state variable and not the real control input, $x_{2}$ is called a virtual control and its desired value $x_{2}^{\text {des }}=\alpha\left(x_{1}, y_{r}, \dot{y}_{r}\right)$ a stabilizing function. For the $z_{1}$-subsystem a CLF $V_{1}\left(z_{1}\right)$ is:

$$
\begin{array}{r}
\dot{V}_{1}=\frac{\partial V_{1}}{\partial z_{1}}\left[f\left(x_{1}\right)+g\left(x_{1}\right) \alpha\left(x_{1}, y_{r}, \dot{y}_{r}\right)\right. \\
\left.-\dot{y}_{r}\right] \leq-W\left(z_{1}\right)
\end{array}
$$

where $W\left(z_{1}\right)$ is positive definite. The difference between the virtual control $x_{2}$ and its desired value $\alpha\left(x_{1}, y_{r}, \dot{y}_{r}\right)$ is defined as the tracking error variable:

$$
z_{2}=x_{2}-x_{2}^{\text {des }}=x_{2}-\alpha\left(x_{1}, y_{r}, \dot{y}_{r}\right)
$$

The system can now be rewritten in terms of the new state $\mathrm{z}_{2}$ as:

$$
\begin{gathered}
\dot{\mathrm{z}}_{1}=\mathrm{f}+\mathrm{g}\left(\mathrm{z}_{2}+\alpha\right)-\dot{\mathrm{y}}_{\mathrm{r}} \\
\dot{\mathrm{z}}_{2}=\mathrm{u}-\frac{\partial \alpha}{\partial \mathrm{x}_{1}}\left[\mathrm{f}+\mathrm{g}\left(\mathrm{z}_{2}+\alpha\right)\right]-\frac{\partial \alpha}{\partial \mathrm{y}_{\mathrm{r}}} \dot{\mathrm{y}}_{\mathrm{r}} \\
-\frac{\partial \alpha}{\partial \dot{\mathrm{y}}_{\mathrm{r}}} \ddot{\mathrm{y}}_{\mathrm{r}}
\end{gathered}
$$

where the time derivative of $\alpha$ can be computed analytically, since it is a known expression. The task is now to find a control law for $\mathrm{u}$ that ensures that $z_{2}$ converges to zero, i.e. $x_{2}$ converges to its desired value $\alpha$. 


$$
V_{2}\left(z_{1}, z_{2}\right)=V_{1}\left(z_{1}\right)+\frac{1}{2} z_{2}^{2}
$$

Taking the derivative of $\mathrm{V}_{2}$ results in:

$$
\begin{aligned}
\dot{V}_{2} \leq-W\left(z_{1}\right)+ & z_{2}\left[\frac{\partial V_{1}}{\partial z_{1}} g+u\right. \\
& -\frac{\partial \alpha}{\partial x_{1}}\left[f+g\left(z_{2}+\alpha\right)\right] \\
& \left.-\frac{\partial \alpha}{\partial y_{r}} \dot{y}_{r}-\frac{\partial \alpha}{\partial \dot{y}_{r}} \ddot{y}_{r}\right]
\end{aligned}
$$

The first term of the above expression is already negative definite by the choice of the stabilizing function $\alpha$ and the bracketed term can be made negative semi-definite by selecting the control Law (Sonneveldt, 2010):

$$
\begin{gathered}
u=-c z_{2}-\frac{\partial V_{1}}{\partial z_{1}} g-\frac{\partial \alpha}{\partial x_{1}}\left[f+g\left(z_{2}+\alpha\right)\right] \\
+\frac{\partial \alpha}{\partial y_{r}} \dot{y}_{r}+\frac{\partial \alpha}{\partial \dot{y}_{r}} \ddot{y}_{r}
\end{gathered}
$$

where the gain $\mathrm{c}>0$.

\section{ii. DESIGN}

The Backstepping design that will be presented is based on the work by Härkegård and Glad (2001).

A few assumptions and simplifications were considered, highlighting:

- The lift coefficient is assumed to be a function of alpha alone;

- No variations in aircraft speed or altitude were considered;

For the angle of attack controller, the aircraft dynamics can be written as:

$$
\begin{aligned}
& \dot{\alpha}=-\frac{L(\alpha)}{m V}+\frac{g}{V}+q \\
& \dot{\mathrm{q}}=\frac{\mathrm{M}(\alpha, \delta)}{\mathrm{I}_{\mathrm{y}}}
\end{aligned}
$$

The Backstepping design yields a virtual control law of the form (Härkegård and Glad, 2001):

$$
u=-k_{2}\left(q-q_{0}+k_{1}\left(\alpha-\alpha_{r e f}\right)\right)
$$

Where $\alpha_{\text {ref }}$ is the desired angle of attack and $q_{0}$ is the pitch rate that makes $\alpha_{\text {ref }}$ the steady state of the aircraft dynamics, given by:

$$
q_{0}=\frac{L\left(\alpha_{r e f}\right)}{m V}-\frac{g}{V}
$$

In this control law, the gain $k_{2}$ must be greater than $k_{1}$ and $k_{1}$ must be such as to counteract the destabilizing tendencies that are due to stall (Härkegård and Glad, 2001):

$$
k_{1}>\max _{\alpha}\left(-\frac{1}{m V} \frac{d L(\alpha)}{d \alpha}\right)
$$

In other words, the gain $k_{1}$ must be greater than the absolute value of the lowest slope of the lift curve past the stall angle. The minimum value of this gain and its physical meaning can be seen more clearly in Figure 5. This Figure was generated using the F16 aircraft dynamics in MATLAB, with $\mathrm{V}=600 \mathrm{ft} / \mathrm{s}$ and $\mathrm{h}=0 \mathrm{ft}$. This flight condition resulted in the highest value for $k_{1}$ across the envelope. It can be seen that the minimum value of $k_{1}$ for the F16 is 0.7 .

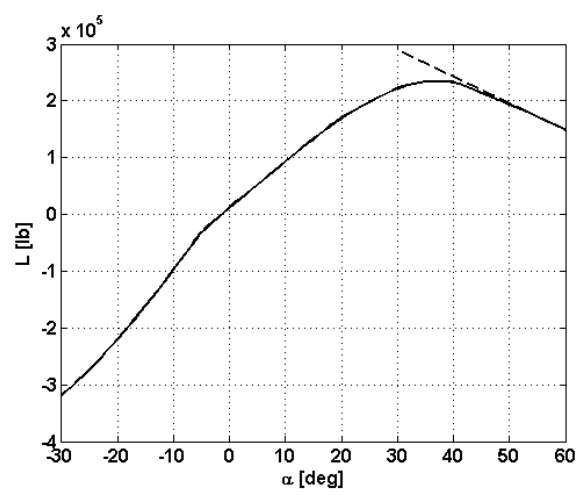

Figure 5. Lift lowest slope past stall.

Once the angle of attack controller is designed, controlling the load factor is a problem very similar to translating pitch acceleration into elevator deflection, presented above. The load factor can be related to the angle of attack by:

$$
n_{z}=-\frac{\bar{q} S}{m g} c_{z}\left(\alpha, \delta_{e}\right)
$$

Where $c_{z}$ is the z-axis aerodynamic force coefficient of the F16 aircraft hence, once knowing a desired load factor and having an instant elevator deflection, the corresponding angle of attack can be obtained by numerical iteration, and the angle of attack controller described above can be used to track a desired load factor. 
Figure 6 shows the Backstepping designed load factor controller structure.

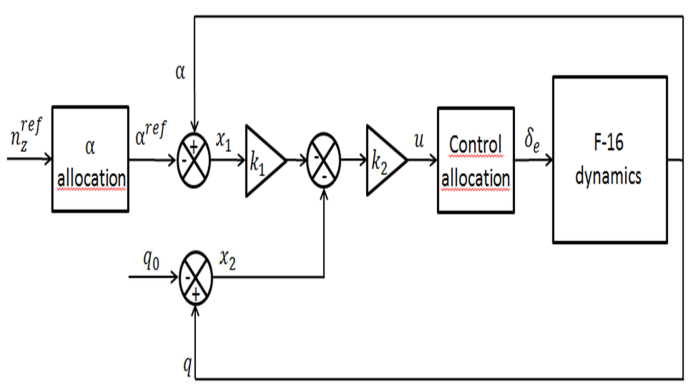

Figure 6. Structure of the Backstepping load factor controller

The Backstepping gains were chosen based on simulation results observation, always keeping in mind the inequality conditions determined in the backstepping design, as $k_{1}=3$ and $k_{2}=5$.

\section{COMPARISON}

In order to compare these control structures, it is necessary to define a set of maneuvers that forces the aircraft to change its airspeed throughout the specified range $(350 \mathrm{ft} / \mathrm{s}$ to $600 \mathrm{ft} / \mathrm{s})$.

The aircraft would track the following load factor trajectory shown in Figure 7, in a total of 20 seconds of simulation.

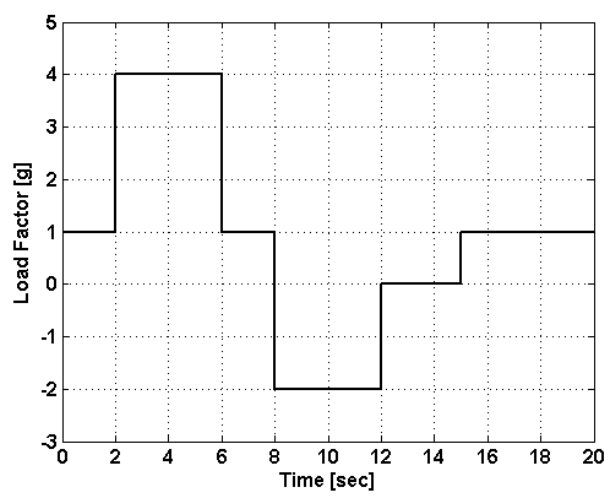

Figure 7. Desired load factor trajectory.

The aircraft starts trimmed at sea level at $600 \mathrm{ft} / \mathrm{s}$ with CG position settled at $0.35 \mathrm{c}$, and the only admissible change in control is in the elevator deflection. Rudder, ailerons and throttle are always kept at their initially trimmed values.

\section{i. RESULTS}

The proposed flight simulation generated the results presented in Figure 8. As required, the aircraft speed changed significantly. The effects of elevator deflection in the aircraft load factor can be clearly seen here.
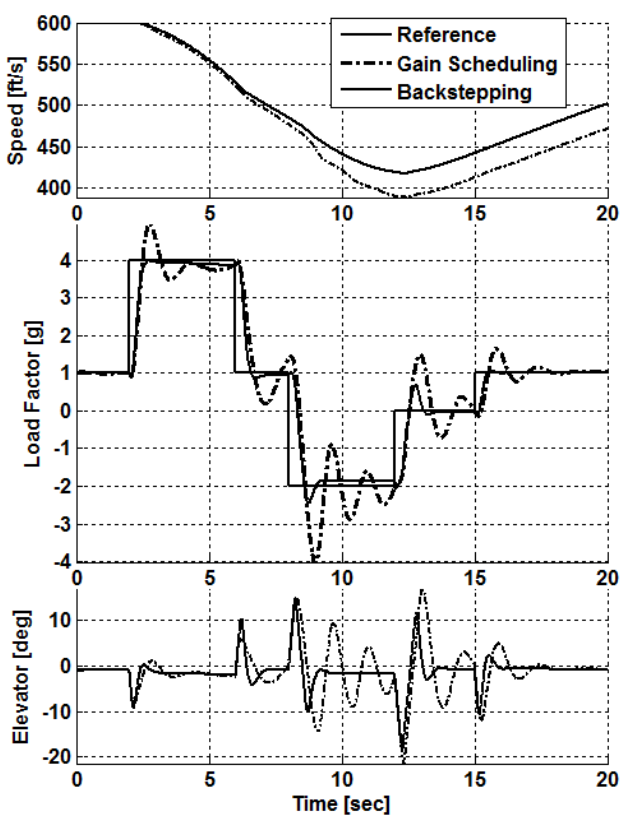

Figure 8. Comparison between Gain Schedule and Backstepping controllers.

\section{CONCLUSIONS AND RECOMMENDATIONS}

From the results, it can be seen that the nonlinear technique, with knowledge of the aircraft model, was able to achieve a significantly better response for load factor control. The simpler design process (only two gains to adjust for all of the flight envelope) coupled with the global stability from Lyapunov theory are two very desirable characteristics of the backstepping technique.

It is important to note that the same Backstepping designed controller could be used in another aircraft by simply substituting the chosen model and readjusting the two gains. For the gain scheduling approach, on the other hand, the new model would have to be linearized and new gains would have to be found for each of the chosen equilibrium points. 
To implement the technique of Backstepping in real time, it is necessary the precise knowledge of the aerodynamic coefficients, therefore, this is possible only after a matching campaign, which would allow the use of coefficients tables coming from the tunnel experiments and flight tests. Another alternative is to estimate these coefficients using the signals coming from the available sensors on the aircraft, this should take care errors estimation.

\section{REFERENCES}

Dagfinn Gangsaas, John Hodgkinson et. al, (2008), Multidisciplinary Control Law Design and Flight Test Demonstration on a Business Jet, AIAA Guidance, Navigation and Control Conference and Exhibit, 18-21 August, Honolulu, Hawaii, EUA.

Alex S. F. da Silva et. al, (2011), A Methodology to Assess Robust Stability and Robust Performance of Automatic Flight Control Systems, Revista Controle \& Automação, vol X..

We Leithead, (1999), Survey of Gain Scheduling: Analysis and Design. International Journal of Control, pp 1001-1025 vol73.

Van Oort R. Eduard (2011) Adaptive Backstepping Control and Safety Analysis for Modern Fighter Aircraft. PhD thesis, Delft University of Technology, Delft, The Netherlands.

Sonneveldt, L., (2010), Adaptive Backstepping Flight Control for Modern Fighter Aircraft. PhD thesis, Delft University of Technology, Delft, The Netherlands.

Chieh Chen, (1996), Backstepping Control Design and Its Applications to Vehicle Lateral Control in Automated Highway Systems.. PhD thesis, University of California, Berkeley, EUA.

Härkegård, O. and Glad, S. T., 2000, A backstepping design for flight path angle control, Decision and Control, 2000. Proceedings of the 39th IEEE Conference on , vol.4, no., pp.35703575 vol.4.

Härkegård, O. and Glad, S. T., 2001. Flight control design using backstepping. In Proc. of the 5th IFAC Symposium on Nonlinear Control Systems, pages 259-264, St. Petersburg, Russia.
Huo, Y. Six-Degree of Freedom Nonlinear F-16 Aircraft Model. Matlab-based Software Package, University of Southern California. Available in http://www.usc.edu/dept/ee/catt/software/, last accessed in $\mathrm{dec} / 2012$.

Lewis, F. L. and Stevens, B. L, 2003. Aircraft Control and Simulation. 2. ed. John Wiley \& Sons Inc.

Mukherjee, J. S. and Pieper, J. K., 2000, Adaptive LQR Gain Scheduling Applied to an Experimental OHS Aircraft. AIAA Guidance, Navigation and Control Conference Exhibit. Denver, CO.

Meyer G. et. al, (1984), Application of nonlinear transformations to automatic flight control, Automatica, pp. 103-107, vol 1.

Lane E. H. and Stengel Fr. , (1988), Flight Control Design Using Non-Linear Inverse Dynamics, Automatica, pp. 471-483, vol 4.

Enns D. et. al, (1994), Dynamic Inversion: an evolving methodology for light control design, International Journal of Control, pp. 71-91, vol 1.

Morales A. et. al (2011), Nonlinear Flight Control Using Backstepping Technique. Brazilian Conference of Control and Applications DINCON. 